\title{
Intra-arterial calcium stimulation test in the investigation of hyperinsulinaemic hypoglycaemia
}

\author{
L J Abernethy, D C Davidson, G L Lamont, R M Shepherd, M J Dunne
}

\begin{abstract}
Objective-To investigate the use of a calcium infusion test in the diagnosis and localisation of insulin secreting tumours in children.

Patients-Three patients with persistent hypoglycaemia of infancy (PHHI).

Procedure-During planned selective coeliac and mesenteric arteriography, serial samples were taken from a catheter in the right hepatic vein for insulin measurement following the injection of calcium gluconate.

Results-In all three children, selective intra-arterial calcium stimulation produced a significant rise in plasma insulin and was of value in localising the pancreatic abnormality in one child. In vitro studies on islets of Langerhans isolated from this patient following partial pancreatectomy showed unresponsive intracellular calcium signalling of the cells when stimulated with high extracellular concentrations of glucose and potassium or with sulphonylurea drugs (tolbutamide), but normal responsiveness to increasing extracellular calcium concentrations.

Conclusions-The findings suggest a functional abnormality of the calcium channel in PHHI and provide a rationale for the reported efficacy of channel blocking drugs in this condition. The role of selective intra-arterial calcium stimulation in the diagnosis of hyperinsulinaemic hypoglycaemia in childhood warrants further investigation.

(Arch Dis Child 1998;78:359-363)
\end{abstract}

Keywords: hyperinsulinaemia; hypoglycaemia; intraarterial calcium stimulation

Royal Liverpool

Children's NHS Trust

Alder Hey, Eaton

Road, Liverpool

L12 2AP

L Abernethy

D C Davidson

G Lamont

University of Sheffield, Department of Biomedical Science,

Sheffield

J Dunne

R M Shepherd

Correspondence to: Dr Davidson.

Accepted 4 November 1997 naemia from other causes of hypoglycaemia, since management strategies differ.

The demonstration of absolute hyperinsulinism or an inappropriately raised plasma insulin concentration with respect to blood glucose is a critical factor in the diagnosis. Low plasma concentrations of free fatty acids and ketone bodies in the presence of significant hypoglycaemia also support the diagnosis. In children, selective pancreatic venous sampling has been shown to be a valuable adjunct to preoperative localisation once the initial diagnosis of hyper- insulinaemia has been made. ${ }^{1}$ However, the role of insulin secretagogues in the investigation of hypoglycaemia in children remains uncertain.

In adults, calcium has been infused by peripheral veins as a provocation test for the diagnosis of insulin secreting islet cell tumours $^{23}$ and by selective intra-arterial injection for tumour localisation. ${ }^{45}$ We report here the results of selective intra-arterial calcium stimulation in three children with severe and recurrent hypoglycaemia and show for the first time how high external calcium ion concentrations increase intracellular $\mathrm{Ca}^{2+}$ in islets of Langerhans in vitro in cases of PHHI.

\section{Methods}

Three children, two females and one male, presented with severe refractory hypoglycaemia. Ages ranged from newborn to 3 years. The diagnosis of persistent hyperinsulinaemic hypoglycaemia of infancy was considered likely and intra-arterial calcium stimulation tests were performed as described at the ages of 4 weeks, 14 months, and 3 years.

\section{TECHNIQUE AND PROCESS}

We performed arterial stimulation and venous sampling during selective coeliac and mesenteric arteriography using calcium as an insulin secretagogue. The technique involved catheterisation of the femoral artery and femoral vein, retrograde positioning of a venous sampling catheter in the right hepatic vein, and selective arterial catheter positioning in the coeliac axis and splenic, superior mesenteric, and gastroduodenal arteries; at each site we gave a rapid bolus injection of calcium gluconate, diluted in $0.9 \%$ saline for a dose of $0.0125 \mathrm{mmol}$ of calcium per $\mathrm{kg}$ body weight in a volume of $5 \mathrm{ml}$. Blood samples were taken from the catheter positioned selectively within the right hepatic vein. Samples were taken immediately before each injection and then at 30 second intervals for 150 seconds. Control samples of peripheral venous blood were taken from the lower inferior vena cava. Insulin, glucose, and calcium measurements were undertaken on each sample.
IN VITRO METHODS

Microfluorimetry with fura-2 was used to monitor changes in the intracellular ionised calcium concentration in intact islets of Langerhans isolated from patient 1 following pancreatectomy. The preparation of tissue was carried out using established methods. ${ }^{6}$ Whole islets were cultured for between 18 and 72 hours in RPMI 1640 medium (Gibco), 


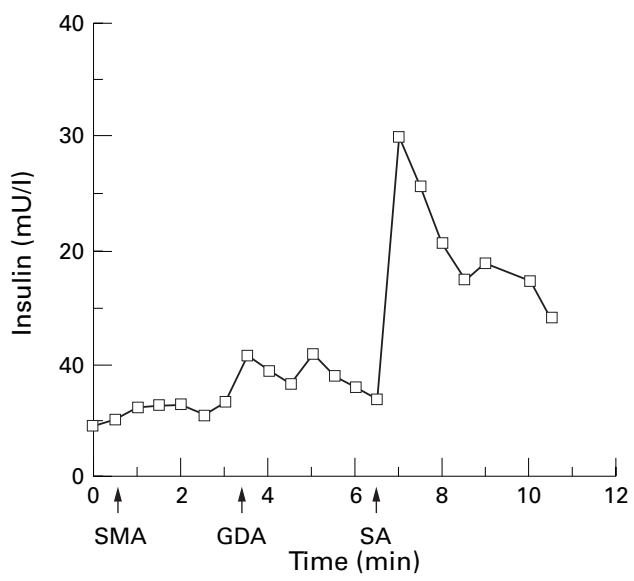

Figure 1 Data from calcium stimulation test in case 1. Graph shows measurements of insulin in blood samples taken from the hepatic veins at 30 s intervals. Selective intra-arterial injections of calcium gluconate $(0.0125$ $\mathrm{mmol} / \mathrm{kg}$ ) are marked on the time axis. $G D A=$ gastroduodenal artery; $S A=$ splenic artery; $S M A=$ superior mesenteric artery.

supplemented with $10 \%$ fetal calf serum and $100 \mathrm{U} / 0.1 \mathrm{mg} / \mathrm{ml}$ penicillin/streptomycin, on coverslips treated with poly-D-lysine $(50 \mu \mathrm{g} / \mathrm{l})$, and for eight minutes in $0.5 \mu \mathrm{M} / \mathrm{ml}$ fura-2-AM (Sigma) in $1 \mathrm{ml}$ of RPMI 1640 medium, both at $37^{\circ} \mathrm{C}$. The composition of basic perfusion medium (in $\mathrm{mmol} / \mathrm{l}$ ) was: $\mathrm{NaCl} 137, \mathrm{KCl}$ 5.36, $\mathrm{MgSO}_{4} 0.81, \mathrm{Na}_{2} \mathrm{PO}_{4} 0.34, \mathrm{KH}_{2} \mathrm{PO}_{4}$ $0.44, \mathrm{NaHCO}_{3} 4.17$, HEPES 10, and $\mathrm{CaCl}_{2}$ 1.26. This medium was gassed with air for 20 minutes, glucose was added at a concentration of $2.02 \mathrm{mmol} / 1$, and the $\mathrm{pH}$ set to 7.4 with $\mathrm{NaOH}$. For studies that involved increasing external $\mathrm{Ca}^{2+}$, the $\mathrm{CaCl}_{2}$ concentration was raised from 1.26 to $10 \mathrm{mmol} / 1$. All experiments were carried out at $37^{\circ} \mathrm{C}$, and an in vitro calibration procedure ${ }^{67}$ was used to estimate changes in $\left[\mathrm{Ca}^{2+}\right]_{\mathrm{i}}$.
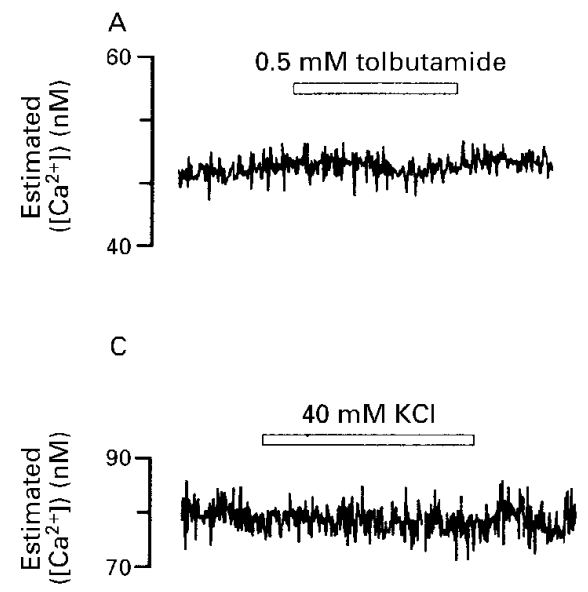

\section{Results}

CASE 1

This patient was a 14 month old, $9 \mathrm{~kg}$ girl with a six month history of persistent refractory hypoglycaemia. At the age of 6 months she presented with an early morning generalised convulsion. Convulsions then recurred at monthly intervals. She was afebrile and her blood glucose was less than $2.00 \mathrm{mmol} / 1$. Attempts to control the early morning hypoglycaemia with nocturnal glucose feeds and with uncooked cornstarch, $2 \mathrm{~g} / \mathrm{kg} /$ day, were unsuccessful. Inappropriate hyperinsulinaemia was demonstrated during a glucagon stimulation test and a fructose tolerance test (plasma insulin 17.6 and $16.7 \mathrm{mU} / 1$, blood glucose 3.20 and $2.70 \mathrm{mmol} / 1$, respectively). Growth hormone, cortisol, and thyroxine concentrations were normal, as were plasma free fatty acids, ketones, and lactate. Drug treatment with chlorothiazide up to $500 \mathrm{mg} /$ day was not effective. Imaging of the pancreas by ultrasound, computed tomography, and magnetic resonance imaging showed no abnormality. Selective arteriography showed no definite focal vascular lesion.

Hepatic venous sampling following selective intra-arterial calcium stimulation was carried out as described (fig 1). The excessive insulin response after selective splenic artery injection (baseline $6.9 \mathrm{mU} / 1$, peak $30.0 \mathrm{mU} / \mathrm{l}$ ) suggested that the lesion was localised to the body or tail. A partial pancreatectomy was performed at 15 months. No focal pancreatic lesion was identified at surgery. Postoperatively the blood sugar stabilised at around 7.00 to $9.00 \mathrm{mmol} / \mathrm{l}$.

Overnight fasting tolerance improved and by six months postoperatively she was thriving and normoglycaemic after overnight fasting. Her neurological development has not been delayed.

Islets of Langerhans were harvested from the resected pancreas and subsequently used for in
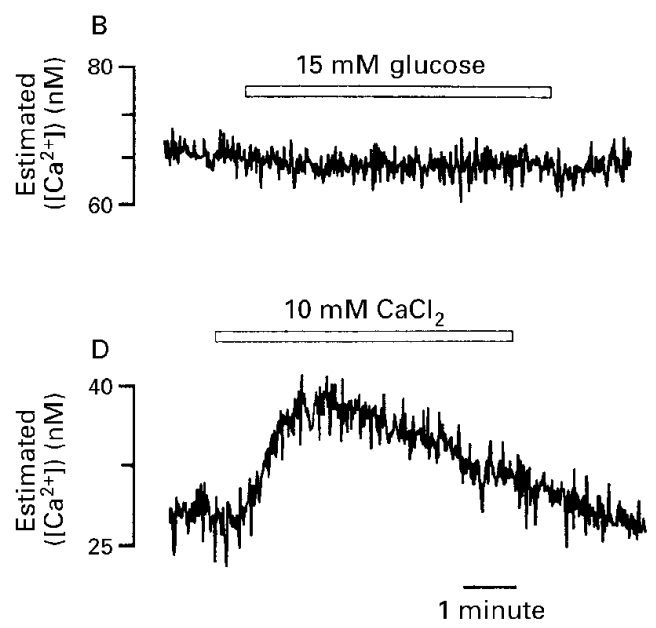

Figure 2 In vitro intracellular calcium signalling events. All data come from single intact islets of Langerhans obtained from case 1. In these studies intact islets are "loaded" with the $\mathrm{Ca}^{2+}$ indicator fura-2. When $\mathrm{Ca}^{2+}$ is increased in the cytosol the calcium fluorochrome changes its fluorescent properties and there is a rise in the ratio of emitted light at $340 / 380 \mathrm{~nm}$ wavelengths. This rise in 340/380 ratio signal is equivalent to a rise in cytosolic calcium concentration. In the patient tissue there were no changes in $\left[\mathrm{Ca}^{2+}\right]_{i}$ when islets were exposed to $0.5 \mathrm{mmol} / \mathrm{l}$ tolbutamide $(n=5 / 6$ islets, panel $\mathrm{A}), 15 \mathrm{mmol} / \mathrm{l}$ glucose $(n=5 / 5$, panel B), or $40 \mathrm{mmol} / \mathrm{l} \mathrm{KC1}(n=3 / 3$, panel $C)$. By contrast, an increase in the external calcium concentration from 1.26 to $10 \mathrm{mmol} / \mathrm{l}$ caused a rise in $\left[\mathrm{Ca}^{2+}\right]_{i}(n=3 / 6$ panel, panel $\mathrm{D})$. 


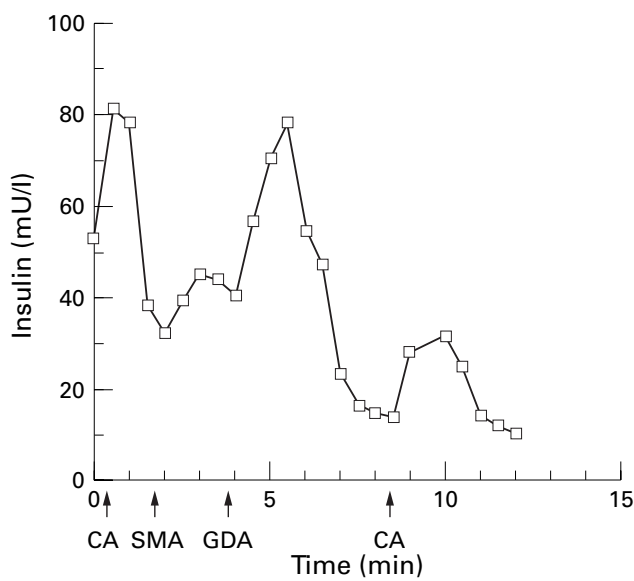

Figure 3 Data from calcium stimulation test in case 2. Graph shows measurements of insulin in blood samples taken from the hepatic veins at 30 s intervals. Selective intra-arterial injections of calcium gluconate $(0.0125$ $\mathrm{mmol} / \mathrm{kg}$ ) are marked on the time axis. $C A=$ coeliac axis; $G D A=$ gastroduodenal artery; $S M A=$ superior mesenteric artery.

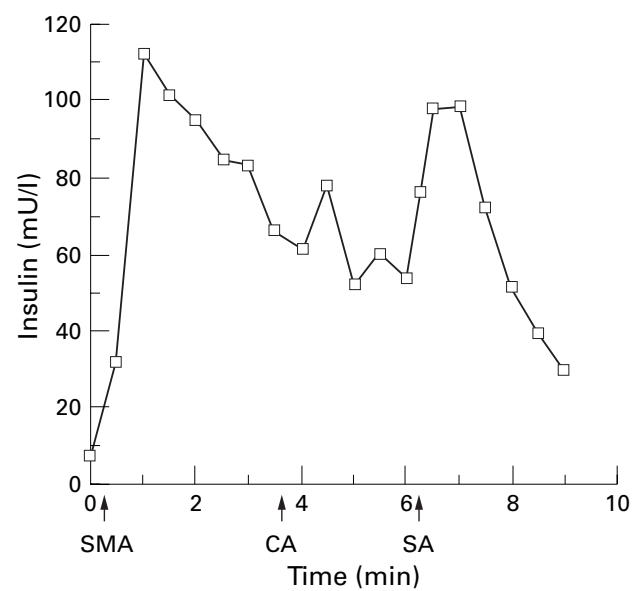

Figure 4 Data from calcium stimulation test on in case 3. Graph shows measurements of insulin in blood samples taken from the hepatic veins at 30 s intervals. Selective intra-arterial injections of calcium gluconate $(0.0125$ mmol $/ \mathrm{kg}$ ) are marked on the time axis. $C A=$ coeliac axis; $S A=$ splenic artery; $S M A=$ superior mesenteric artery.

vitro studies of cell function by electrophysiological and microfluorimetric techniques. Intracellular calcium signalling events in islets isolated from this patient were unresponsive to stimulation with glucose $(15 \mathrm{mmol} / \mathrm{l})$, high extracellular potassium ( $40 \mathrm{mmol} / \mathrm{l})$, and to the sulphonylurea tolbutamide $(0.5 \mathrm{mmol} / \mathrm{l})$ (fig $2)$. By contrast, however, when the external calcium concentration was increased from 1.26 to $10 \mathrm{mmol} / 1$, this led to a subsequent rise in the free intracellular calcium (fig 2). In normal $\beta$ cells such increases in the external calcium cause insulin release by raising the concentration of intracellular cytosolic $\mathrm{Ca}^{2+}$ through mechanisms that are not dependent upon voltage gated calcium channels. ${ }^{8}$ Therefore these in vitro findings provide a rationale for explaining how intra-arterial calcium stimulation leads to insulin release in patients with a cellular defect associated with the ionic control of insulin secretion. In this patient the insulin responsiveness to intra-arterial calcium stimulation was also useful in her preoperative assessment.
CASE 2

A 3 year old, $14.0 \mathrm{~kg}$ girl had a history of vomiting and a brief generalised convulsion. There was a past history of febrile convulsions, but her milestones of development were normal. Clinical examination was unremarkable. She had ketonuria, which accounted for $64 \%$ of the total organic acid excretion. During a 12 hour fast, the blood glucose fell to $2.3 \mathrm{mmol} / \mathrm{l}$ and there was marked ketonuria $(+++)$.

The situation stabilised for six months without specific treatment, but then she again experienced early morning hypoglycaemia. This was refractory to treatment with uncooked cornstarch and nocturnal glucose feeds. Following an induced fast of 14 hours there was no significant rise in the plasma free fatty acids, ketones, or lactate, and the blood glucose was $4.9 \mathrm{mmol} / 1$. Cortisol, growth hormone, and thyroid function tests were all normal. The plasma insulin concentration was normal at initial presentation $(0.9 \mathrm{mU} / 1$ with respect to a blood glucose concentration of $2.30 \mathrm{mmol} / \mathrm{l}$ ) but was high after an overnight fast $(31.80 \mathrm{mU} / 1$ with a blood glucose of 5.6 $\mathrm{mmol} / \mathrm{l})$. Selective arteriography with intraarterial calcium injection was performed according to the protocol (fig 3). This showed significant peaks of insulin from all sites. Pancreatectomy is not planned at present. The child has regular nocturnal glucose drinks and supplemental glucose polymer by day. Drug treatment with chlorothiazide, diazoxide, or calcium channel blocking drugs is currently being considered.

\section{CASE 3}

This boy was born to a 27 year old primipara at 39 weeks' gestation by emergency caesarean section because of pregnancy induced hypertension and fetal distress. Birth weight was 4.12 $\mathrm{kg}$. He was admitted to the neonatal unit at 18 hours of age because of severe hypoglycaemia, which was initially controlled with early and frequent feeding. Intravenous glucose was required, with carbohydrate supplements added to the feeds and oral hydrocortisone. Currently he has extra carbohydrate and diazoxide, $25 \mathrm{mg} / \mathrm{kg} /$ day.

Investigations confirmed inappropriate oversecretion of insulin $(29.7 \mathrm{mU} / \mathrm{l}$ with blood glucose of $3.0 \mathrm{mmol} / \mathrm{l})$. During the intra-arterial calcium stimulation test the insulin rose from a baseline value of $6.5 \mathrm{mU} / 1$ to $113.0 \mathrm{mU} / 1$ after superior mesenteric arterial injection, with smaller rises after coeliac axis and splenic artery injection (fig 4).

The baby's father had fits secondary to hypoglycaemia during infancy and was considered to have hyperinsulinaemia.

A limited pancreatectomy was undertaken on this patient. He now has epilepsy controlled with sodium valproate and diabetes controlled by diet.

\section{Discussion}

There has been a recent attempt to unravel the diagnostic difficulties associated with hyperinsulinaemic hypoglycaemia in childhood and the newborn. ${ }^{9}$ The diagnosis of hyperinsulinae- 
mia is by the demonstration of inappropriately high plasma insulin concentrations for an associated blood glucose concentration. In the three children reported here we found selective intra-arterial injection of calcium gluconate to be an effective insulin secretagogue though the test was of limited value in localising the pancreatic abnormality. In case 1 the excessive insulin response following splenic artery injection suggested that the lesion was localised to the body or tail, but in cases 2 and 3 the pattern of insulin production following selective arterial injection was of no localising value. Dubois et al, using a similar invasive technique but selectively sampling pancreatic venous insulin, ${ }^{1}$ have found the procedure useful in the preoperative localisation of insulin secreting lesions in children. However, in their study plasma insulin concentrations were measured during hypoglycaemia and insulin secretagogues were not used.

In adults, Kaplan et al evaluated calcium infusion over a two hour period as a provocation test for insulinomas, and described it as safe and effective. ${ }^{2}$ Their study included one child with surgically proved islet cell hyperplasia, but there was no significant change in the plasma insulin concentrations during the calcium infusion tests in that patient. In their patients, calcium was given by peripheral vein infusion, whereas in our patients it was given by direct and selective intra-arterial bolus.

In Brunt's study, ${ }^{3}$ rapid infusion of calcium into the peripheral circulation produced only a small rise in mean plasma insulin concentrations, but in patients with insulinomas there was a rapid and large peak, similar to the pattern observed in our patients.

Our results confirm that the insulinotropic response to selective intra-arterial calcium injections in adults with insulinomas also occurs in children suspected of having persistent hyperinsulinaemic hypoglycaemia of infancy (nesidioblastosis). Although experience is clearly limited, this investigation may prove useful in the investigation of complex cases of hypoglycaemia in infancy, particularly when surgical management is considered. Further evaluation in carefully selected children with persistent or refractory hypoglycaemia seems warranted.

Recently, two important studies have revealed that the pathogenesis of PHHI in the familial ${ }^{10}$ and non-familial ${ }^{6}$ forms of the disease is associated with the loss of ionic control of insulin release. In normal insulin secreting cells, stimulatory concentrations of glucose depolarise the cell membrane potential and this leads to the influx of calcium by voltage dependent mechanisms. Calcium influx then triggers the release of insulin by calcium regulated exocytotic events: fusion of secretory granules with the plasma membrane and release of their contents. The link in stimulusresponse events involves the closure of potassium channels in the plasma membrane. As these channels are metabolically coupled to glucose through changes in the intracellular ATP:ADP ratio, ATP sensitive potassium channels are recognised as playing a key part in

\section{Key messages}

- Calcium mediates insulin secretion at a cellular level

- In persistent hyperinsulinaemic hypoglycaemia of infancy (PHHI) there is a defect in control of intracellular calcium in islet cells

- High external calcium levels increase intracellular calcium in islet cells from patients with PHHI

- Intra-arterial calcium gluconate injection stimulates insulin secretion from the pancreas in PHHI

the normal events that govern insulin secretion. It is significant therefore that defects in the genes that encode the subunits of this channel are linked to familial disease ${ }^{11} 12$ and that these defects lead to the loss of functional ATP sensitive potassium channels in children with severe forms of PHHI. ${ }^{610}$ The loss of these ion channels in PHHI patients causes the cell membrane potential to be "spontaneously" depolarised and constantly generating action potentials that result in calcium influx and increased intracellular concentrations of calcium. ${ }^{6}$ It has been suggested that hyperactivity of voltage gated calcium channels as a result of the absence of $\mathrm{K}_{\mathrm{ATP}}$ channels leads to hypersecretion of insulin in PHHI patients; this is supported by the fact that oral administration of the calcium channel antagonist nifedipine can alleviate the symptoms of hypoglycaemia in PHHI. ${ }^{13}$

The identification of this unique cellular defect in PHHI patients also explains why insulin secreting cells are poorly responsive to insulinotropic agents; these normally mediate insulin release through changes in the cell membrane potential that trigger voltage dependent increases in intracellular calciumthat is, glucose, raised external $\mathrm{KCl}$, and so $\mathrm{on}^{14}$ - and this has implications for the use of insulin secretagogues in intra-arterial insulin stimulation tests.

In the wider context there may be a need to reconsider the therapeutic options for unresponsive hyperinsulinaemic hypoglycaemia in infancy and childhood in the light of increasing understanding of the pathophysiology of this condition. ${ }^{13}$ Previously, the failure to respond to medical treatment has been recognised as an indication for early surgery to avoid neuroglycopenic sequelae, but partial pancreatectomy has a later morbidity: malabsorption and diabetes mellitus. ${ }^{15}$ Calcium channel blocking drugs seem to provide a rational therapeutic option before final resort to partial pancreatectomy.

We thank Dr C D Bedford, consultant paediatrician at Warrington Hospital NHS Trust, who referred case 3 for investigation.

1 Dubois J, Brunelle F, Touati G, et al. Hyperinsulinism in children: diagnostic value of pancreatic venous sampling children: diagnostic value of pancreatic venous sampling in 25 cases. Pediatr Radiol 1995;25:512-16.

2 Kaplan EL, Rubenstein AH, Evans R, Lee CH, Klementschitsch P. Calcium infusion: a new provocative test for insulinomas. Ann Surg 1979;190:501-7. 
3 Brunt LM, Veldhuis JD, Dilley WG, et al. Stimulation of insulin secretion by a rapid intravenous calcium infusion in patients with B-cell neoplasms of the pancreas. F Clin

Endocrinol Metab 1986;62:210-16.

Kung AWC, Chan FL, Tam SCF, Lam KSL. Case report: localization of occult insulinoma by intra-arterial stimulation with calcium and venous sampling technique. Clin Radiol 1992;46:55-6.

5 Doppman JL, Miller DL, Chang R, Shawker TH, Gorden P, Norton JA. Insulinomas: localization with selective intraarterial injection of calcium. Radiology 1991;178:237-41.

6 Kane C, Shepherd RM, Squires PE, et al. Loss of functional $\mathrm{K}_{\mathrm{ATP}}$ channels in B-cells causes persistent hyperinsulinaemic hypoglycaemia in infancy. Nat Med 1996;2:1344-7.

7 Grynkiewicz G, Poenie M, Tsien RY. A new generation of $\mathrm{Ca}^{2+}$ indicators with greatly improved properties. $f \mathrm{Bio}$ Chem 1985;260:3440-50.

8 Wollheim CB, Sharp GWG. Regulation of insulin release by

9 Milner RDG. Nesidioblastosis unravelled. Arch Dis Child 1996;74:369-72.
10 Dunne MJ, Kane C, Shepherd RM, et al. Familial persistent hyperinsulinemic hypoglycaemia of infancy and mutations
in the sulfonylurea receptor. $N$ Engl f Med 1997;336:7036.

11 Thomas PM, Cote CJ, Wohlik N, et al. Mutations in the sulphonylurea receptor gene in familial hyperinsulinemic hypoglycaemia of infancy. Science 1995;268:426-9.

12 Glaser B, Chiu KC, Anker R, et al. Familial hyperinsulinism maps to chromosome $11 \mathrm{p} 14-15.1,30 \mathrm{cM}$ centromeric to the insulin gene. Nat Genet 1994;7:185-8

13 Lindley KJ, Dunne MJ, Kane C, et al. Ionic control of B-cell function in nesidioblastosis. A possible therapeutic
role for calcium channel blockade. Arch Dis Child 1996;74:373-8.

14 Kaiser N, Corcos AP, Tur SA, et al. Regulation of insulin release in persistent hyperinsulinaemic hypoglycaemia of infancy studied in long-term culture of pancreatic tissue. Diabetologia 1990;33:482-8.

15 Spitz L, Bhargava RK, Grant DB, Leonard JV. Surgical treatment of hyperinsulinaemic hypoglycaemia in infancy treatment of hyperinsulinaemic hypoglycaemia 